\title{
Uma Hipótese Psicanalítica Acerca do Desencadeamento da Anorexia na Psicose
}

\author{
Cláudia Henschel de Lima ${ }^{1}$ \\ ${ }^{1}$ Universidade Federal Fluminense, RJ, Brasil.
}

\author{
Débora Assis de Souza \\ ${ }^{1}$ Universidade Federal Fluminense, RJ, Brasil.
}

\begin{abstract}
Resumo: Este artigo tem como objeto a pesquisa etiológica sobre a anorexia. Nesse sentido, expõe os resultados da pesquisa teórica em psicanálise conduzida em 2016, com recursos públicos para implementação de bolsa de iniciação científica. Por meio da análise e organização do levantamento conceitual sobre o tema no campo da psicopatologia clássica e da psicanálise, foi possível problematizar a validade da classe de transtorno alimentar, definida na quinta edição do Manual Diagnóstico e Estatístico de Transtornos Mentais (DSM-5) para elucidar o quadro sintomático da anorexia, e conduzir uma pesquisa etiológica, em psicanálise, sobre os determinantes psíquicos do desencadeamento da anorexia. A pesquisa interrogou a consistência do diagnóstico psicanalítico de psicose para alguns casos em que vigorariam características clínicas que, no DSM-5, induziriam ao diagnóstico de anorexia e formulou a hipótese de que o diagnóstico de psicose, tal como definido pela psicanálise, elucida a etiologia de determinados casos de anorexia em que vigora a recusa do alimento a serviço da cadaverização, da desvitalização e da rigidez identificatória à denominação sou anoréxica. A retomada do caso de Ellen West, paciente do psiquiatra suíço Ludwig Binswanger, cumpre neste artigo exatamente o papel de verificar a hipótese da pesquisa de que a recusa do alimento, a serviço da cadaverização e da desvitalização, pode ser tributária da psicose.
\end{abstract}

Palavras-chave: Anorexia, Psicose, Psicanálise, Diagnóstico, Psicopatologia.

\section{A Psychoanalytic Hypothesis about the Effects of Anorexia in Psychosis}

\begin{abstract}
This paper is an etiological research on anorexia exposing the results of a psychoanalysis study conducted in 2016 with help of a scientific initiation scholarship. Analysis and organization of the conceptual survey on the subject allowed to question the validity of the class of Eating Disorder defined in the fifth edition of DSM-5 and to elucidate anorexia symptoms. We evaluated the psychic determinants that trigger anorexia and verified the consistency of diagnoses of psychosis for cases in which there would be clinical characteristics that, as per the DSM-5, would induce a diagnosis of anorexia. Psychosis was hypothesized to cause certain cases of anorexia where food refusal in favor of cadaverization, devitalisation and rigidity. The Ellen West case involving a patient of the Swiss psychiatrist Ludwig Binswanger served to confirm the hypothesis of this study.
\end{abstract}

Keywords: Anorexia, Psychosis, Psychoanalysis, Diagnosis, Psychopathology.

\section{Una Hipótesis Psicoanalítica acerca del Desencadenamiento de la Anorexia en la Psicoses}

Resumen: El presente artículo tiene como objeto la investigación etiológica sobre la anorexia. Para ello, expone los resultados de la investigación teórica en psicoanálisis conducida en 2016 con recursos públicos para la implementación de una beca de iniciación científica. 
Por medio del análisis y organización del levantamiento conceptual sobre el tema en el campo de la psicopatología clásica y del psicoanálisis, fue posible problematizar la validez de la clase de trastorno alimenticio, definida en la quinta edición del Manual Diagnóstico y Estadístico de los Trastornos Mentales (DSM-5) para la elucidación del cuadro sintomático de la anorexia, y conducir una investigación etiológica en psicoanálisis sobre los determinantes psíquicos del desencadenamiento de la anorexia. La investigación interrogó la consistencia del diagnóstico psicoanalítico de psicosis para algunos casos en que pudieran aplicarse características clínicas que, en el DSM-5, inducirán al diagnóstico de anorexia, y formuló la hipótesis de que el diagnóstico de psicosis, tal como es definido por el psicoanálisis, elucida la etiología de determinados casos de anorexia en los cuales se rige el rechazo del alimento al servicio de la cadaverización, de la desvitalización y de la rigidez identificatoria a la denominación soy anoréxica. Este artículo reanuda el caso de Ellen West, paciente del psiquiatra suizo Ludwig Binswanger, para verificar exactamente la hipótesis de que la negativa del alimento, al servicio de la cadaverización y de la desvitalización, puede ser tributaria de la psicosis.

Palabras clave: Anorexia, Psicosis, Psicoanálisis, Diagnóstico, Psicopatología.

\section{Introdução}

Este artigo tem como tema a pesquisa etiológica sobre a anorexia e expõe os resultados da pesquisa teórica em psicanálise, conduzida em 2016, com recursos públicos para implementação de bolsa de iniciação científica.

Por meio da análise e organização do levantamento conceitual sobre o tema no campo da psicopatologia clássica e da psicanálise, foi possível problematizar a validade da classe de Transtorno Alimentar, definida na quinta edição do Manual Diagnóstico e Estatístico dos Transtornos Mentais (DSM-5), para elucidar o quadro etiológico da anorexia e conduzir uma pesquisa, em psicanálise, sobre os determinantes psíquicos de seu desencadeamento.

O Quadro 1, elaborado no curso da pesquisa, sintetiza a evolução do diagnóstico dos transtornos alimentares entre a terceira e quinta edição do DSM na direção de uma amplificação dos grupos nosológicos e do recuo da investigação etiológica.

O Quadro 1 ressalta a elevada quantidade de grupos nosológicos para os transtornos alimentares estabelecidos com base em uma sintomatologia comportamental, descritiva e ateórica. Esse ateorismo empírico tem, como efeito, uma inflação diagnóstica tanto no interior da classe diagnóstica como na multiplicação das categorias no campo da pesquisa diagnóstica.

A anorexia é um fenômeno clínico severo que apresenta as taxas mais elevadas de mortalidade entre os transtornos psicopatológicos (AlckminCarvalho, Santos, Rafihi-Ferreira, \& Soares, 2016).
Isso confirma a observação de Lutenberg (2014) sobre a gravidade do quadro clínico das patologias atuais, com risco de vida para o paciente, e da qual se infere a dimensão de urgência clínica que é desconhecida pelo próprio paciente.

\section{Quadro 1.}

Evolução na tipologia dos transtornos alimentares.

\begin{tabular}{|c|c|}
\hline $\begin{array}{l}\text { Edições } \\
\text { do DSM }\end{array}$ & $\begin{array}{c}\text { Evolução na tipologia dos transtornos } \\
\text { alimentares }\end{array}$ \\
\hline DSM-III & $\begin{array}{l}\text { Anorexia nervosa e bulimia nervosa } \\
\text { como grupos nosológicos específicos } \\
\text { (American Psychiatric Association, 1980). }\end{array}$ \\
\hline $\begin{array}{l}\text { DSM- } \\
\text { III-TR }\end{array}$ & $\begin{array}{l}\text { Distinção entre: } \\
\text { 1. Transtorno alimentar (anorexia nervosa). } \\
\text { 2. Perturbação do comportamento } \\
\text { alimentar (bulimia nervosa, pica e } \\
\text { transtorno ruminativo da infância). }\end{array}$ \\
\hline $\begin{array}{l}\text { DSM-IV } \\
\text { e DSM } \\
\text { IV-TR }\end{array}$ & $\begin{array}{l}\text { Os transtornos alimentares estão } \\
\text { divididos em dois grupos: anorexia } \\
\text { nervosa e bulimia nervosa. } \\
\text { Pica e transtornos ruminativos da } \\
\text { infância são incluídos na seção de } \\
\text { Transtornos Alimentares da Primeira } \\
\text { Infância (American Psychiatric } \\
\text { Association, 2000). }\end{array}$ \\
\hline DSM-V & $\begin{array}{l}\text { Anorexia nervosa, bulimia nervosa, pica, } \\
\text { transtorno de ruminação, transtorno } \\
\text { da evitação ou restrição alimentar e } \\
\text { transtorno da compulsão alimentar } \\
\text { são categorizados como transtornos } \\
\text { alimentares (American Psychiatric } \\
\text { Association, 2014). }\end{array}$ \\
\hline
\end{tabular}


Do DSM-5 (American Psychiatric Association, 2014) é possível extrair as características clínicas mais evidentes da anorexia para a psiquiatria contemporânea: perda intensa de peso, obtida pela restrição autoimposta de alimentos e pela negação do sujeito com relação a seu estado de saúde, medo intenso de adquirir peso ouse tornarobeso, adespeito deestarcom peso abaixo do normal, e distorção da imagem corporal. Tais características se referem ao funcionamento comportamental do paciente, demonstram a gravidade e urgência clínica do quadro sem, no entanto, evidenciar uma interrogação acerca de sua etiologia. Avançando no detalhamento das características clínicas descritivas da anorexia, o DSM-5 (APA, 2014) distingue, ainda, seus dois subtipos: o tipo "restritivo" e o tipo "compulsão alimentar purgativa", conforme sintetizados no Quadro 2, também elaborado ao longo da pesquisa.

Quadro 2.

Critérios diagnósticos para anorexia nervosa no DSM-5.

A. Restrição da ingestão calórica em relação às necessidades, levando a um peso corporal significativamente baixo no contexto de idade, gênero, trajetória do desenvolvimento e saúde física. Peso significativamente baixo é definido como um peso inferior ao peso mínimo normal ou, no caso de crianças e adolescentes, menor do que o minimamente esperado.

B. Medo intenso de ganhar peso, engordar ou comportamento persistente que interfere no ganho de peso, mesmo que este esteja significativamente baixo.

C. Perturbação no modo como o próprio peso ou a forma corporal são vivenciados. Influência indevida do peso ou da forma corporal na autoavaliação ou ausência persistente de reconhecimento da gravidade do baixo peso corporal atual.

Determinar o subtipo:

(F50.01) Tipo restritivo: durante os últimos três meses, o indivíduo não se envolveu em episódios recorrentes de compulsão alimentar ou comportamento purgativo (i.e., vômitos autoinduzidos ou uso indevido de laxantes, diuréticos ou enemas). Esse subtipo descreve apresentações nas quais a perda de peso seja conseguida essencialmente por meio de dieta, jejum e/ou exercício excessivo.

(F50.01) Tipo compulsão alimentar purgativa: nos últimos três meses, o indivíduo se envolveu em episódios recorrentes de compulsão alimentar purgativa (i.e., vômitos autoinduzidos ou uso indevido de laxantes, diuréticos ou enemas).

Especificar se:

Em remissão parcial: depois de terem sido preenchidos previamente todos os critérios para anorexia nervosa, o Critério A (baixo peso corporal) não foi mais satisfeito por um período sustentado, porém ou o Critério B (medo intenso de ganhar peso ou de engordar, ou comportamento que interfere no ganho de peso), ou o Critério C (perturbações na autopercepção do peso e da forma) ainda está presente.

Em remissão completa: depois de terem sido satisfeitos previamente todos os critérios para anorexia nervosa, nenhum dos critérios foi mais satisfeito por um período sustentado.

Especificar a gravidade atual:

O nível mínimo de gravidade se baseia, em adultos, no índice de massa corporal (IMC) atual (ver a seguir) ou, para crianças e adolescentes, no percentil do IMC. Os intervalos apresentados a seguir são derivados das categorias da Organização Mundial da Saúde para baixo peso em adultos; para crianças e adolescentes, os percentis do IMC correspondentes devem ser usados. O nível de gravidade pode ser aumentado de maneira a refletir sintomas clínicos, o grau de incapacidade funcional e a necessidade de supervisão.

Leve: $\mathrm{IMC} \geq 17 \mathrm{~kg} / \mathrm{m} 2$

Moderada: IMC 16-16,99 kg/m2

Grave: IMC 15-15,99 kg/m2

Extrema: IMC $<15 \mathrm{~kg} / \mathrm{m} 2$

Fonte: Adaptado de American Psychiatric Association (2014). 
Da mesma forma, a leitura dos critérios diagnósticos para a anorexia deixa claro que o DSM-5 não avança a descrição da fenomenologia clínica apresentada na direção de sua etiologia, deslocando-se rapidamente para a identificação comportamental dos seus subtipos e especificações. De fato, o medo intenso de ganhar peso, com ocorrência de restrição da ingesta calórica em relação às necessidades - mesmo com peso já inferior ao peso mínimo normal - e a perturbação no modo como o próprio peso ou a forma corporal são vivenciados indicam a irrupção de uma perturbação na relação entre o indivíduo e a experiência de seu corpo. E que apenas é indicada sem que haja, por exemplo, uma interrogação referente à etiologia psíquica dessa perturbação para além da descrição de sua fenomenologia observável. O divórcio com a pesquisa etiológica em psicopatologia é, portanto, inseparável da ascensão de uma concepção ateórica cujo resultado é a inflação diagnóstica, já mencionada anteriormente.

O estudo de Alckmin-Carvalho et al. (2016) corrobora com esse ponto, ao apontar que tratamentos ambulatoriais e unidades de internação apresentam índices desanimadores de aderência ao tratamento e à recuperação da anorexia a ponto de constatarem que, para esses casos, a recaída e a demanda de novo tratamento parecem ser mais regra do que exceção. Os autores citam dois estudos longitudinais com pacientes que deram entrada em uma unidade de internação com diagnóstico de anorexia. O primeiro deles foi conduzido nos anos 1970 e acompanhou, durante 41 anos, pacientes com diagnóstico de anorexia. O estudo registrou percentual de $5 \%$ de óbitos, $39 \%$ de recuperação completa e $66 \%$ de recaída e nova demanda de tratamento. $\mathrm{O}$ segundo estudo longitudinal acompanhou, durante noventa meses, uma amostra de 243 mulheres com anorexia e observou que apenas $33 \%$ das participantes se recuperaram completamente, com percentual de recaída de um terço após o tratamento.

$\mathrm{Na}$ direção contrária da perspectiva ateórica do DSM, dois estudos de Recalcati (1997, 2011), seguindo o marco teórico da psicanálise, já exploravam a relação entre os sintomas clínicos da anorexia e os processos psíquicos em jogo em sua formação, verificando, assim, a necessidade de elucidar tais sintomas à luz dos processos de recalcamento e foraclusão - típicos da constituição das estruturas psíquicas (neurose e da psicose) - e do destino assumido pela pulsão em cada estrutura. Dessa forma, a referência de Recalcati aponta para a íntima relação entre teoria e clínica, ao considerar que as características clínicas da anorexia são dependentes do funcionamento psíquico na neurose e na psicose, e não são indicativas da classe dos transtornos alimentares, conforme sugere o DSM-5.

A pesquisa que está na origem deste presente artigo interrogou, então, a consistência do diagnóstico psicanalítico de psicose para alguns casos em que vigorariam características clínicas que, no DSM-5, induziriam ao diagnóstico de anorexia. E formulou a hipótese de que o diagnóstico de psicose, tal como definido pela psicanálise, elucida a etiologia de determinados casos de anorexia nos quais vigora a recusa do alimento a serviço da cadaverização, da desvitalização e da rigidez identificatória à denominação sou anoréxica.

A apresentação de algumas referências clássicas em psicopatologia cumpre o papel de expor a complexidade da pesquisa etiológica sobre o desencadeamento da anorexia, ao mesmo tempo em que expõe o cuidado com que os autores de época - Charles Lasègue, William Withey Gull, Jean-Martin Charcot, Pierre Janet, Ludwig Binswanger, Jules Cotard consolidaram essa pesquisa em torno do eixo clínica-teoria-psicopatologia. Com isso, espera-se evidenciar a precisa dimensão desse eixo na condução da pesquisa diagnóstica no século XIX, bem como sua atualidade para o avanço nas referências mais atuais em psicanálise sobre o tema em articulação com a pesquisa etiológica sobre a psicose. Obedecendo a esse recurso metodológico à psicopatologia clássica, o caso de Ellen West, paciente do psiquiatra suíço Ludwig Binswanger, cumpre neste artigo exatamente o papel de interrogar a validade da hipótese de que a recusa do alimento está a serviço da cadaverização e da desvitalização, podendo ser tributária da psicose.

O artigo dividirá a descrição dos resultados em três partes. A primeira posiciona a psicopatologia clássica como atual na pesquisa psicanalítica sobre a etiologia psíquica da anorexia, por definir a anorexia como fenômeno clínico, e não como classe diagnóstica. A segunda parte retoma a síndrome de Cotard para interrogar os fenômenos clínicos da anorexia à luz da hipótese de psicose. O impacto dessa hipótese sobre o entendimento da anorexia será analisado na terceira parte, com a retomada do testemunho de Ellen West. 


\section{Método}

Por ser uma pesquisa teórica, a metodologia empregada foi o levantamento de referências conceituais sobre o tema da anorexia, extraídas do campo de investigação da psicopatologia clássica e da psicanálise.

Recorreu-se, em primeiro lugar, às formulações dos principais autores em psicopatologia clássica que, direta e indiretamente, pesquisaram a etiologia da anorexia: Charles Lasègue, William Withey Gull, Jean-Martin Charcot, Pierre Janet, Ludwig Binswanger e Jules Cotard. Em segundo lugar, foram retomadas as referências de Sigmund Freud e do psicanalista francês Jacques Lacan, articuladas direta e indiretamente ao tema da anorexia. No caso específico das referências de Lacan, deu-se preferência àquelas que abordam diretamente a síndrome de Cotard e a psicose. E, em terceiro lugar, foram trabalhadas as referências conceituais contemporâneas no domínio de investigação psicanalítica da psicose - como é o caso de JacquesAlain Miller, Jean-Claude Maleval e Massimo Recalcati.

Ao longo da pesquisa, foi coletada a amostra de dez estudos de caso publicados. No entanto, para este artigo, decidiu-se pela retomada de algumas passagens do testemunho de Ellen West, paciente do psiquiatra suíço Ludwig Binswanger, a fim de interrogar a validade da hipótese de psicose para esse caso, em que se evidencia a recusa do alimento a serviço da cadaverização e da desvitalização.

\section{Resultados e discussão}

O avanço das edições do DSM pela psiquiatria anglo-americana evidencia uma reordenação do diagnóstico diferencial em torno das classes de transtornos, apostando na superação dos marcos classificatórios da psicopatologia clássica. A decisão pela clínica dos transtornos impôs um divisor importante no campo epistemológico da pesquisa psicopatológica: de um lado, o ateorismo do DSM e, de outro, a psicopatologia psicanalítica. Observando a ordenação dos transtornos alimentares no DSM-5, tal como se encontra nos Quadros 1 e 2 deste artigo, verifica-se que sua base ateórica, dissociada da hipótese etiológica, impede o avanço da pesquisa diagnóstica na direção de delimitar a especificidade clínica da recusa de alimento no funcionamento psíquico e sua redução aos tipos comportamentais (anorexia nervosa, bulimia nervosa, pica, transtorno de ruminação, transtorno da evitação ou restrição alimentar e transtorno da compulsão alimentar). Tomando como referência a hipótese deste artigo, essa base ateórica inviabiliza uma interrogação diagnóstica relativa à possível correlação entre anorexia e psicose, a partir do testemunho da recusa de alimento na experiência subjetiva dos fenômenos hipocondríacos e da rigidez identificatória à denominação de sou anoréxica.

A decisão pelo ateorismo não é sem consequências. O estudo recente conduzido por Redmond (2017) mostra procedimento de redução dos índices clínicos para diagnóstico de psicose, operado pelo DSM-IV-TR, quando comparados às classificações psicopatológicas clássicas: o DSM-IV-TR isola trinta índices clínicos para diagnóstico da esquizofrenia, enquanto Bleuler isolara noventa e Kraepelin, 75 índices clínicos. E, nesse campo da redução, Redmond (2017) assinala a tendência do psiquiatra clínico a reduzir ainda mais, orientando-se por apenas quatro ou cinco índices dentre os trinta presentes no DSM-IV-TR. Essa redução produz uma ênfase maior nas perturbações cognitivas (delírios, alucinações, discurso desorganizado) e comportamentais (comportamento grosseiramente desorganizado ou catatônico), e exclui uma pesquisa mais precisa sobre as variadas perturbações de corpo, elencadas na antiga categoria de esquizofrenia cinestésica descrita em 1957, e recuperadas pelo psicanalista Jacques-Alain Miller (2012) ao formular a externalidade corporal como índice clínico para o diagnóstico de psicose.

Essas observações são de fundamental relevância, pois revelam o empobrecimento da pesquisa diagnóstica em torno das perturbações hipocondríacas na psicose em casos identificados pelo DSM como de anorexia. O levantamento conceitual no domínio da psicopatologia clássica sobre a anorexia evidenciou, no entanto, o traço distintivo da psicopatologia clássica antes da ascensão do DSM: a atenção ao modo como o sujeito localiza a recusa do alimento a partir da experiência de estar no mundo.

\section{Atualidade da psicopatologia clássica na pesquisa psicanalítica sobre anorexia}

Em Da anorexia histérica, Lasègue (1873/1998) formula a hipótese de que a anorexia é uma forma clínica da histeria e localiza seu desencadeamento em meninas e mulheres jovens. O artigo contém oito estudos de casos com jovens entre 18 e 32 anos, em que o autor verifica a especificidade da anorexia histérica e sua etiologia. 
Ele identifica três fases na formação de quadro clínico e isola sua etiologia. A primeira fase se caracteriza pela diminuição na ingestão de alimentos com o objetivo de obter alívio para as dores gástricas experienciadas pelas pacientes após cada refeição. A segunda fase é denominada de "perversão mental" e é situada por Lasègue (1873/1998) como a fase de consolidação do quadro principal da anorexia. Nesta fase, as tentativas de induzir as pacientes a se alimentarem são ineficazes, evidenciando o estado psíquico de resistência a se alimentar. A fase final já evidencia o avanço desse estado de resistência e suas consequências: amenorreia, ressecamento da pele e sensação de desfalecimento.

Quanto à etiologia, Lasègue (1873/1998) isola na recusa, um estado mental comum a todos os casos estudados. Esse estado mental explicaria a ocorrência, de um lado, do excesso de quietude "verdadeiramente patológica" testemunhada por meio de uma fórmula típica - "não conseguia, era mais forte do que eu e, além do mais, estava passando bem" (Lasègue, 1873/1998, p. 171) - e, de outro, a irrupção de um estado de contentamento, de entusiasmo verdadeiramente patológico em que as pacientes não têm a dimensão da gravidade de seu quadro clínico. Quanto à direção de tratamento, o autor defendeu uma conduta bastante atenta por parte do médico, já que o estado mental de recusa de comer é inseparável de um quadro maníaco de bulimia para expulsão de calorias e adições em geral.

A atenção devida à evolução desse quadro clínico deve ser o eixo da conduta clínica já que a paciente nesse estado só aceita ajuda no momento em que o quadro maníaco fracassa e cede lugar ao sadness-sign (Lasègue, 1873/1998).

Simultaneamente, WilliamWithey Gull (1874/1997) apresenta três estudos de caso à Clinical Society of London, em que concentrou maior atenção aos efeitos da inanição prolongada do que ao fator psíquico: perda de apetite, emagrecimento extremo, fraqueza, inquietação, amenorreia e leve constipação. Seguindo o procedimento investigativo do século XIX, o autor registra em desenho o quadro clínico das pacientes antes e depois do tratamento, conforme reproduzido na Figura 1.

O registro em desenho feito por Gull (1874/1997) ressaltava o traço clínico do emagrecimento extremo, da apepsia histérica, como indicador da anorexia. Contrariando a suposição da época, de que o traço de emagrecimento poderia estar correlacionado à tuberculose, o autor associara esse traço clínico a um estado mental mórbido caracterizado pela decisão deliberada de deixar de comer presente na histeria sem, no entanto, haver evidências quanto à ocorrência dos clássicos sintomas de contratura, convulsão e hemiplegia.
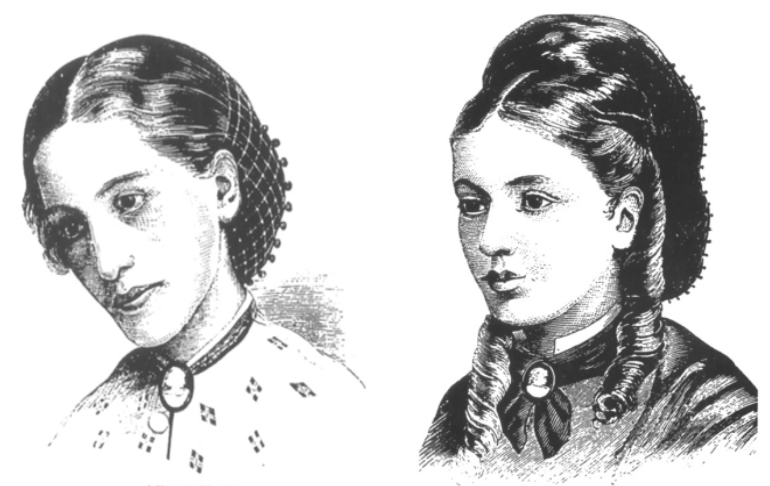

Miss A. Número 1 Miss A. Número 2
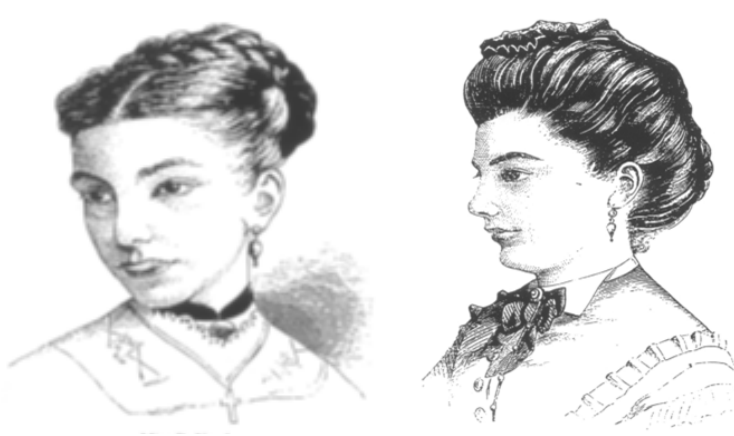

Miss B. Número 1 Miss B. Número 2

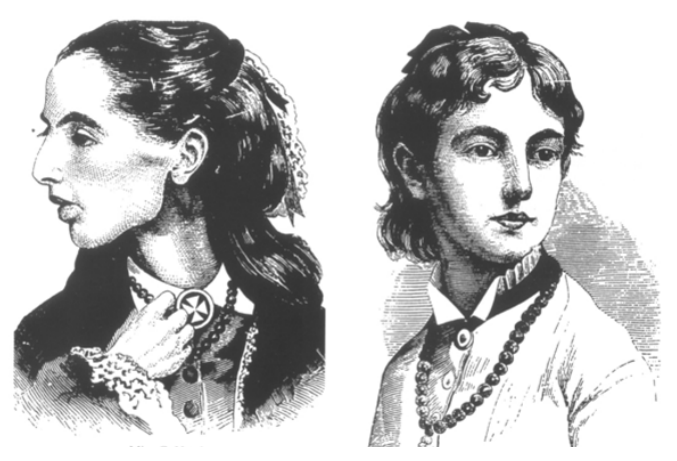

Miss C. Número 1 Miss C. Número 2

Figura 1

Esboço das pacientes estudadas por Gull (1874/1997).

No quadro do avanço da investigação psicopatológica em torno da anorexia no século XIX, ressalta-se ainda a referência de Jean-Martin Charcot no mesmo sentido de correlacionar o fenômeno clínico da anorexia à etiologia da histeria. Entre os anos de $1882 \mathrm{e}$ 
1885, Charcot desenvolveu 25 estudos de caso com o objetivo de descrever as várias formas da "grande histeria". Dentre esses casos, Charcot relata o de uma jovem que havia estado muito obesa por cerca de seis meses e que passara a, sistematicamente, recusar todo tipo de alimento sem apresentar problemas de deglutição ou estomacais como correlatos fisiológicos para tal recusa. Ele isola, então, na ocorrência da ideia fixa de obesidade ou fobia de peso, o traço psicopatológico que estaria na motivação ao jejum da anorexia (Silverman, 1997).

Em 1903, Pierre Janet apresenta o estudo de caso de Nadia, de 22 anos, como anorexia mental, ressaltando o seguinte conteúdo discursivo da paciente durante as consultas: "você acredita que eu estou tão magra quanto da última vez? Por favor, diga-me que serei sempre magra" (Cordás \& Claudino, 2002, p. 4, tradução nossa). Seguindo a hipótese de Lasègue (1873/1998) sobre a associação entre histeria e anorexia, Janet distinguiu duas formas de anorexia com base na presença ou ausência de apetite: a forma obsessiva, na qual o apetite estava preservado, e a forma histérica, em que se evidenciava a perda do apetite.

A fundação da psicanálise, na passagem do século XIX para o século XX, traz o debate vivo com a psicopatologia da época em torno da relevância da hipótese da casualidade inconsciente na etiologia da histeria.

Se o conjunto das referências conceituais extraídas da psicopatologia clássica trabalhava com a hipótese de que a anorexia era uma manifestação clínica da histeria, para Freud, a própria investigação etiológica da histeria exigia da teoria a formulação de novos conceitos: inconsciente, pulsão e recalcamento. Dessa forma, para Freud, a recusa do alimento não elucidaria o desencadeamento da anorexia; antes, ela era o efeito de um processo psíquico mais fundamental. O caso de Emmy Von N. é, nesse sentido, exemplar. Freud (1893/1982) estabelece uma articulação entre a recusa alimentar e o sintoma conversivo a partir da evidência clínica de que a abulia de Emmy seria o resultado da ligação entre a ideia de comer e lembranças repugnantes de refeições frias que era obrigada a ingerir junto com seus irmãos doentes.

A investigação acerca do processo psíquico, subjacente à recusa do alimento, avança em Freud para além da clínica da histeria. De fato, No "Rascunho G", Freud (1895/1982) dedica-se a detalhar a etiologia da melancolia elaborando uma hipótese essencial para o reconhecimento clínico de seu desencadeamento: na melancolia ocorre a retração pulsional e o melancólico experiencia essa retração como perda da libido. O "Rascunho G" (Freud,1895/1982) evidencia que o processo psíquico de constituição da psicose melancólica será, para Freud, a chave conceitual para o entendimento da anorexia. De fato, referindo-se ao exemplo clínico da anorexia, o autor sustenta que esta é uma manifestação da melancolia: "a paciente afirma que não se alimenta simplesmente porque não tem nenhum apetite; não há qualquer outro motivo. Perda do apetite - em termos sexuais, perda da libido" (Freud, 1895/1982, p. 150).

Essa posição epistemológica contraria a hipótese de Lasègue (1873/1998), Gull (1874/1997), Charcot (Silverman, 1997) e Janet (Cordás \& Claudino, 2002), que localizam na recusa do alimento o fator etiológico da anorexia histérica. Ela exige, então, interrogar pela etiologia da recusa do alimento situando nos conceitos de recalcamento e rejeição a chave de interpretação teórica para elucidar sua etiologia na neurose e na psicose. Seguindo essa interrogação, Freud (1895/1982) sustenta que a anorexia seria uma manifestação clínica do processo de luto pela perda da libido, típica da melancolia.

A hipótese de Freud é de extrema sofisticação na medida em que conduz a pesquisa etiológica nesse campo para a elucidação da recusa do alimento à luz do luto pela perda da libido. Esse ponto reaparece no texto de Freud (1911/1982) quando interroga a ocorrência das ideias de emagrecimento em Schreber e formula a hipótese de que a etiologia de tais ideias deveria ser buscada na ocorrência da hemorragia pulsional típica do processo de retração do investimento pulsional na psicose. Avançando na referência específica da hemorragia pulsional típica da psicose melancólica, observa-se, em "Luto e melancolia" (Freud, 1917 [1915]/1982), o aprofundamento dessa teorização sobre a hemorragia pulsional por retração do investimento pulsional em relação ao objeto para o eu, ressaltando o efeito melancólico de avanço da sombra do objeto sobre o eu. Essa referência conceitual confere à recusa do alimento na anorexia e seus efeitos clínicos de emagrecimento extremo, o caráter de manifestação clínica do luto pela hemorragia pulsional. A imagem do corpo cada vez mais magro expõe a sujeição do funcionamento psíquico, na anorexia, à essa hemorragia. 
O debate com a psicopatologia também foi fundamental no trabalho de Jacques Lacan (1955-1956/2002) e, em especial, na elaboração de uma teoria psicanalítica sobre a foraclusão, que:

1. Distingue, estruturalmente, o processo de recalcamento e a conversão do afeto na neurose histérica e o processo de foraclusão e a irrupção dos fenômenos elementares na psicose.

2. Esclarece a etiologia de fenômenos clínicos da psicose - desde o automatismo mental até os fenômenos de corpo verificados na esquizofrenia e na síndrome de Cotard, típica da melancolia.

\section{Atualidade da síndrome de Cotard e diagnóstico psicanalítico de psicose}

A síndrome de Cotard foi inicialmente descrita por Jules Cotard, em 1880, para compreensão dos processos subjacentes ao quadro melancólico. Seu traço específico é a ocorrência do delírio de negação, cuja forma típica (forma especial de delírio hipocondríaco melancólico) se caracteriza pela ocorrência de ideias de negação de órgãos internos ou orifícios (boca, ânus), de estar podre, sem sangue até a radicalidade da inexistência ou da morte e que se estende a familiares e amigos, a todo o tempo e a todo o campo da realidade (o mundo deixa de existir). Ao mesmo tempo em que se instalam tais ideias, pode ocorrer, paradoxalmente, o delírio de imortalidade e enormidade, cujo testemunho é dado pela afirmação de ser um morto-vivo (Cotard, 1882/1998).

Com a finalidade de especificar os delírios de perseguição e de negação, Cotard (1882/1998) caracteriza o delírio de perseguição pela ocorrência desde a hipocondria inicial até a megalomania, e o delírio de negação por uma profunda depressão com ansiedade. No primeiro, o sujeito acusa seus perseguidores; no segundo, a acusação incide sobre a própria personalidade do sujeito até a radicalidade de sua negaçãocaracterizada como "negação hipocondríaca" (a negação que atinge a integridade do corpo e dos órgãos) típica da psicose melancólica e sem correlato em uma lesão anátomo-fisiológica identificável. Nesse caso, o sujeito não tem mais estômago, nem cérebro, nem cabeça. Não se alimenta mais, não digere mais, não troca mais a roupa e recusa os alimentos, além de, algumas vezes, não liberar matéria fecal:

Perguntamos seu nome? Eles não têm nome. Sua idade? Não têm idade. Onde nasceram? Não nas- ceram. Quem eram seu pai e sua mãe? Não tem pai, nem mãe, nem mulher, nem filhos. Perguntamos se estão com dor de cabeça, no estômago ou em alguma parte do corpo. Não tem cabeça, nem estômago; alguns até não tem corpo.... Para alguns a negação é universal, nada existe mais, eles mesmo não são mais nada (Cotard, 1882/1998, p. 157).

Nessa condição, o sujeito recusa indistintamente todos os alimentos por não ter estômago, porque "a carne e outro nutriente cai-lhes como couro na barriga" ou, ainda, por não ter como pagar. Além disso, devido à culpa, o sujeito pode escolher seus alimentos: como penitência, ingere pão seco ou se priva de sobremesa. Assim, já em Cotard (1882/1998), testemunha-se o posicionamento da recusa de alimento no campo da experiência crepuscular da psicose:

Em geral ela é total e tem por objeto indistintamente todos os alimentos; os doentes se recusam a comer porque não têm estômago, "a carne e outro nutriente cai-lhes como couro na barriga", porque os danados não comem, porque não têm com o que pagar. Alguns, no entanto, dominados por um delírio de culpa ou de ruína menos intenso, escolhem seus alimentos: comem somente pão seco por penitência ou privam-se de sobremesa (Cotard,1882/1998, p. 89).

Em contrapartida, no delírio de perseguição, a recusa do alimento está relacionada à certeza quanto a seu envenenamento. Considerando a descrição da síndrome de Cotard e, em particular, a irrupção da recusa do alimento à luz da negação hipocondríaca característica da síndrome e a certeza de envenenamento do alimento, no delírio de perseguição, é possível avançar no referencial psicopatológico para a associação entre anorexia e psicose. Alinhando a elaboração da teoria sobre a psicose ao debate com a psicopatologia, ressalta-se em Lacan uma referência direta à síndrome de Cotard e ao processo de constituição da psicose em $\mathrm{O}$ seminário, livro 2: o eu na teoria e na técnica da psicanálise (1954-1955/1985). No debate com Alexandre Koyré sobre a ruptura imposta pela revolução científica no século XVII, Lacan responde à pergunta: "por que os planetas não falam?", estabelecendo uma analogia com os testemunhos das pacientes com síndrome de Cotard: 
Aquilo a que elas se identificaram é uma imagem a qual falta toda e qualquer hiância, toda e qualquer aspiração, todo o vazio do desejo, isto é, o que constitui propriamente a propriedade do orifício bucal. Na medida em que se opera a identificação do ser à sua pura e simples imagem, não há tampouco lugar para a mudança, ou seja, para a morte. É justamente disto que se trata na temática delas - elas, ao mesmo tempo, estão mortas e não podem mais morrer, elas são imortais - como o desejo (Lacan, 1954-1955/1985, pp. 299-300).

Essa analogia com a síndrome de Cotard é, na verdade, a ocasião para definir o valor assumido pelo corpo na psicose e, em especial, o que Freud (1895/1982, 1917 [1915]/1982) situa como sendo os efeitos clínicos da hemorragia pulsional na melancolia. Atenta-se, aqui, para a possibilidade de se interrogar sobre o estatuto da recusa de alimento e da rigidez identificatória à luz do destino assumido pelo sujeito na síndrome de Cotard:

1. Experiência subjetiva de vazio como propriedade do orifício bucal e indicativa do que Freud (1917[1915]/1982) localizara como a hemorragia pulsional na melancolia.

1. Identificação do ser a sua pura e simples imagem como exposição do luto pela perda do objeto.

\section{Certeza de que se está morto e de que se é, ao mesmo tempo, imortal}

Retomando a pesquisa da etiologia da anorexia à luz da psicose, interroga-se aqui qual seria o valor assumido pela cadaverização na experiência de vazio e na identificação do ser a sua pura e simples imagem. A indicação de Lacan (1954-1955/1985) acerca da experiência do vazio na síndrome de Cotard é considerada por Cottet (1997) e Recalcati $(1997,2011)$, que avançam na elucidação do diagnóstico diferencial entre neurose e psicose a partir da distinção entre duas experiências subjetivas: a falta e o vazio.

Com base, então, na formulação de Freud (1895/1982, 1911/1982, 1917[1915]/1982), a respeito do destino da retração pulsional na neurose e na psicose, e de Lacan (1954-1955/1985) a respeito da síndrome de Cotard, Cottet (1997) e Recalcati $(1997,2011)$ definem dois critérios etiológicos para distinguir neurose e psicose: a experiência subjetiva da falta e a do vazio.

A experiência subjetiva da falta corresponde ao efeito de mortificação determinado pela incidência do significante sobre o funcionamento pulsional.
Cottet (1997) exemplifica esse efeito recorrendo a um testemunho que Ferenczi endereça a Freud:

Ontem, domingo à tarde, antes de Madame G chegar, estado de profunda depressão com insuperável tendência para chorar. . . . Este sintoma que se poderia classificar de histérico devo interpretá-lo como sinal de luto: eram manifestações de sentimentos na ocasião do adeus a Gizella.... Em companhia de Gizella e somente dela, melhora o meu humor e sinto outra vez interesse pela ciência (Ferenczi, 1916, citado por Cottet, 1997, p. 26).

A leitura do trecho acima deixa claro como a etiologia do estado depressivo de Ferenczi dependia da presença ou ausência de sua mulher, Gizella. Em contraste à etiologia da falta, localizada nos efeitos de mortificação da pulsão pelo significante, a experiência subjetiva do vazio está relacionada ao processo de retração da pulsão em relação ao significante.

Na experiência do vazio, a pulsão vigora hegemonicamente sobre o sujeito, seja pela hemorragia pulsional, nos casos de melancolia (Freud, 1895/1982), seja pelo desligamento da pulsão em relação ao mundo externo na esquizofrenia. Recalcati (1997) toma essa experiência como referência para pensar certos casos de anorexia nos quais vigoraria um apetite de morte, uma tendência ao zero. O testemunho de um paciente, reproduzido pelo autor oferece a dimensão dessa experiência, contrária à experiência da falta articulada à mortificação pelo significante:

Quando me preencho de tudo, quando alcanço o ponto extremo da repugnância, me sinto além desse asco, além de tudo, em um estado de ausência, de não-ser e não-pensamento.... O vazio que sinto dentro de mim quando consigo prorrogar o jejum até o limite é mais real que qualquer outra coisa. É tão real, é uma presença tão absoluta, que todo o demais desaparece, deixa de existir. Existe só esse vazio (Recalcati, 1997, p. 51).

A distinção entre falta e vazio, por Cottet (1997) e Recalcati (1997), permite esclarecer a etiologia psíquica da recusa do alimento na anorexia, tomando como referência o diagnóstico diferencial entre neurose e psicose. Definidas nesses termos, as experiências de falta e vazio funcionam como índices importantes na elucidação da recusa do alimento na anorexia - desde 
o conjunto dos fenômenos clínicos já elencados no século XIX, por Lasègue (1873/1998), até os fenômenos elementares relacionados ao corpo e ao sentido e a verdade na psicose (petrificação do corpo na síndrome de Cotard, delírio de envenenamento da comida).

A partir do estudo de caso de uma paciente depressiva, Castanet e De Georges (2012) retomam a denominação de doença da mentalidade, reportada por Miller (1998), para se referir a casos em que o paciente dá o testemunho de uma experiência de corpo em que a anatomia está em pedaços. Os autores localizaram no encontro com o sexo a conjuntura de desencadeamento da experiência dramática de estar diante do abismo da dissolução do corpo:

Adotava um estilo clínico, ora horrorizado, ora irônico, para descrever, como observadora, as manobras que os homens fazem com seu corpo, sua relação tão estranhamente interessada pelos pedaços de sua anatomia que parecem soltos uns dos outros. O que sente é, ao mesmo tempo, uma desfalicização radical e uma insustentável depreciação (Castanet \& De Georges, 2012, p. 33).

Na paciente, a estatuificação a protege da dissolução corporal. Ela se define como uma pedra, em referência direta a seu primeiro nome e à identificação com a virgem santa. A partir, então, da localização de um recurso ao nome para se preservar da dissolução do corpo, os autores recorrem ao conceito de superidentificação intercrítica a papéis sociais, demonstrada por Tellenbach para os casos de melancolia, e propõem a denominação de suplência intercrítica ressaltando o trabalho psíquico de apagamento do vazio aberto pela foraclusão, conforme expõe a Figura 2 .

$\begin{array}{ll}\begin{array}{l}\text { Phi0-empuxo a ser ninguém/ } \\ \text { Solução compensatória } \rightarrow\end{array} & \text { Superidentificação } \\ \text { dissolução anatômica } & \text { Nome próprio }\end{array}$

Figura 2

O processo de superidentificação no quadro da foraclusão.

Fonte: Adaptado de Castanet \& De Georges (2012).

O esquema elaborado por Castanet e De Georges (2012) deixa claro que a experiência de vazio responde à falência fálica típica da foraclusão (PHI0). E é experienciada por meio de fenômenos elementares relativos ao corpo, como é o caso da dissolução do corpo no estudo de caso de Castanet e De Georges (2012), e como síndrome de Cotard, em que o sujeito dá o testemunho da inexistência dos órgãos, de seu apodrecimento, até a radicalidade de sua inexistência e paradoxal imortalidade. A superidentificação intercrítica, nesses casos, seria uma solução imaginária compensatória em relação à experiência subjetiva de vazio foraclusivo, em relação a um quadro de completo deserto referencial, e produziria uma continuidade rígida de ser já mencionada anteriormente neste artigo: ser uma pedra ou, mesmo, ser anoréxica.

Retomando o levantamento preliminar das referências em psicopatologia sobre o tema da anorexia realizado ao longo deste trabalho e à luz dessas referências mais atuais, há a indicação para a pesquisa diagnóstica de que não só é fundamental preservar a correlação mais clássica entre histeria e anorexia como também avançar no aprofundamento da investigação de quadros clínicos de anorexia em que vigora uma identificação imaginária (sou anoréxica) sustentada por um conjunto de práticas de caráter metódico e rígido: obediência estrita a dietas e, no extremo, abstinência alimentar, autoimposição de exercícios físicos cada vez mais intensos, testemunhos regulares relativos ao mal-estar de habitar o laço social, que chega ao extremo de seu desinvestimento massivo.

Essa solução imaginária é, também, abordada no estudo de Maleval (2014) em torno da etiologia e diagnóstico das psicoses ordinárias. Por meio do levantamento clínico de uma série de experiências subjetivas - que vão desde a localização de um excesso de consistência no Outro até a experiência mais radical dos fenômenos de autoscopia - o autor localiza a ocorrência hegemônica de identificações ordinárias em espelhamento (uma verdadeira deriva imaginária, por sua característica de deslocamento metonímico no eixo a-a') como parte do trabalho psíquico de elaboração de uma estratégia para compensação da foraclusão do Nome-do-Pai. O autor comenta o estudo de caso de Madame T, exposto por Czermak, para ressaltar o modo de funcionamento da identificação imaginária - já detectável anos antes do desencadeamento da psicose, como é o caso de Madame T:

Desde sua infância ... eu percebi que ela era muito influenciável, ao menor contato ela aderia muito facilmente. . . Q Quando ela estava em boa companhia, então ela era formidável, apreciada. Mas quando ela estava em má com- 
panhia. . . . ela poderia ter se prostituído. . . . Ela não tem um comportamento único. Ela faz isso porque não tem direção pessoal. Ela é bastante mitônoma. . . . quando ela era pequena, com seis anos, teve na escola uma colega, mais velha e mais burra. Ela agia como essa colega: tomava para si, imitava. . . Com seu primeiro amante, ela era tão mentirosa e desajustada quanto ele. Isso quer dizer que falar com ela não é suficiente, é a imagem (Czermak, 1986, citado por Maleval, 2014, p. 118).

A observação sobre a pregnância do imaginário no campo das psicoses leva Maleval (2014) a interrogar por que determinados sujeitos que recorrem a esse modo de compensação mais frágil para produzir uma solução que é compensatória à foraclusão do Nome-do-Pai acabam procurando tratamento psicanalítico e o que os leva ao tratamento. $O$ autor estabelece um elenco variado de motivos que evidenciam essa fragilidade na compensação pelo imaginário: desde a deflagração de um episódio depressivo, uma inibição nos estudos ou no trabalho, um transtorno psicossomático, até a vontade de se transformar em psicanalista ou mesmo porque alguém lhe comentou a respeito do modo de funcionamento da psicanálise. Além desses motivos variados, não raramente se observa, nesses casos, a ocorrência de uma gama variada de fenômenos clínicos de fobia, obsessões e conversões indicando o vazio na subjacente ao funcionamento psíquico - no lugar da fantasia - e a tentativa de construção da solução compensatória.

A referência recente, na literatura psicanalítica, ao tema da psicose (Maleval, 2014, Miller, 2012, Redmond, 2017) e comentada neste artigo preserva, em primeiro lugar a recomendação de Lacan (1977/1992) para que o psicanalista não retroceda diante da clínica da psicose e, em segundo lugar, a importância da detecção do diagnóstico para a direção de tratamento. Tais referências avançam na investigação etiológica acerca da psicose e apontam para o aprofundamento dessa pesquisa na direção de reconhecer a fenomenologia clínica decorrente do processo de foraclusão do Nome-do-Pai e seu correlato a nível da função fálica. Este trabalho reconhece nesse avanço a possibilidade de contribuir para a clínica da recusa do alimento na anorexia, elucidando-a como uma posição subjetiva inteligível à luz do processo de foraclusão.

\section{A anorexia de Ellen West seria tributária do desencadeamento da psicose?}

Ellen West foi admitida na Clínica Bellevue de Kreuzlingen, no início do séculoXX, ondeL. Binswanger era o superintendente. Ela dá cabo de sua própria vida aos 33 anos com uma dose mortal de veneno.

O diagnóstico da paciente sofreu variações enormes e, mesmo após sua morte, não houve concordância quanto ao diagnóstico: seu médico de cabeceira a diagnosticou com psicastenia; um segundo profissional formulou o diagnóstico de histeria; um terceiro levantou a hipótese de neurose obsessiva grave com oscilação maníaco-depressiva; Kraepelin sugeriu o diagnóstico de melancolia; Bleuler e Binswanger concordaram no diagnóstico de esquizofrenia e outro psiquiatra supôs uma constituição psicótica de evolução progressiva - e todos os três discordaram do diagnóstico de neurose obsessiva com oscilação maníaco-depressiva. Mas quais eram os sintomas apresentados por Ellen West que estariam na origem dessa controvérsia diagnóstica?

Villegas i Besora (1997) ordenara os sintomas apresentados pela paciente a partir de seu testemunho identificando os fenômenos clínicos elencados no DSM-3 para anorexia (317.10): medo intenso de ganhar peso e ficar gorda, perda significativa de peso, recusa em manter o peso dentro dos limites de normalidade e amenorreia a partir dos 29 anos. A perda de peso dessa paciente fora documentada pelo autor, segundo os valores e as práticas e rituais para perda de peso, e sintetizada neste artigo no Quadro 3.

\section{Quadro 3}

Curva ponderal da paciente de Binswanger segundo Villegas i Besora (1997).

\begin{tabular}{|c|c|c|}
\hline Idade & Peso & $\begin{array}{l}\text { Práticas e rituais relacionados } \\
\text { a dietas e uso de laxantes }\end{array}$ \\
\hline 24 anos & $78 \mathrm{~kg}$ & $\begin{array}{l}\text { Dietas e ingestão de } 60 \text { a } \\
70 \text { comprimidos laxantes, } \\
\text { tomates e } 20 \text { laranjas por dia. }\end{array}$ \\
\hline 28 anos & $72 \mathrm{~kg}$ & $\begin{array}{l}\text { Dietas, exercícios exagerados, } \\
\text { ingestão } 60 \text { a } 70 \text { comprimidos } \\
\text { de laxantes, tomates e } \\
20 \text { laranjas por dia. }\end{array}$ \\
\hline 31 anos & $47 \mathrm{~kg}$ & $\begin{array}{l}\text { Dietas, exercícios exagerados, } \\
\text { ingestão } 60 \text { a } 70 \text { comprimidos } \\
\text { de laxantes, tomates e } \\
20 \text { laranjas por dia. }\end{array}$ \\
\hline
\end{tabular}


...continuação

\begin{tabular}{|c|c|c|}
\hline Idade & Peso & $\begin{array}{l}\text { Práticas e rituais relacionados } \\
\text { a dietas e uso de laxantes }\end{array}$ \\
\hline 32 anos & $42 \mathrm{~kg}$ & $\begin{array}{l}\text { Dietas, exercícios exagerados, } \\
\text { ingestão de laxantes, tomates } \\
\text { e } 20 \text { laranjas por dia. }\end{array}$ \\
\hline 33 anos & $46 / 47 \mathrm{~kg}$ & $\begin{array}{l}\text { Dietas, exercícios exagerados, } \\
\text { ingestão } 60 \text { a } 70 \text { comprimidos } \\
\text { de laxantes, tomates e } \\
20 \text { laranjas por dia. }\end{array}$ \\
\hline 35 anos & $41 \mathrm{~kg}$ & $\begin{array}{l}\text { Ingestão de } 60 \text { a } 70 \\
\text { comprimidos de laxantes, } \\
\text { vegetais, tomates e } \\
20 \text { laranjas por dia. }\end{array}$ \\
\hline
\end{tabular}

Fonte: Adaptado de Villegas i Besora (1997).

Apesar da referência ao DSM, Villegas i Besora (1997) frisa que a etiologia de seus fenômenos clínicos não pode ser explicada pela hipótese de uma anorexia instalada na adolescência. Ao contrário, tais fenômenos são a expressão de uma crise subjetiva que se instala e ocupa a vida da paciente por cerca de13 anos, até a precipitação de sua morte. Uma parte de seu testemunho, destacada pelo autor, dá a exata noção dessa crise:

Já que um único critério de ação era descobrir se uma coisa me tornava gorda ou magra, todas as coisas logo perderiam o significado.... O que costumava ser um prazer para mim agora é uma tarefa, algo inerentemente sem sentido, projetado para ajudar a passar as horas. O que antes parecia um objetivo na vida, toda cultura, todo esforço, todas as conquistas agora são pesadelos sombrios e avassaladores que me aterrorizam (Ellen West, citada por Villegas i Besora, 1997, p. 15).

É claro o desenho de um "antes e depois" na experiência subjetiva de Ellen West e a necessidade de se interrogar pelo marco dessa distinção na vida da paciente, ou pelo que Lacan (1957-1958/1998) definira como uma desordem na junção do sujeito com seu sentimento de vida, típica do processo de foraclusão. A leitura de referências sobre o caso (Tosta Berlinck \& Magtaz, 2008; Villegas i Besora,1997) permite delimitar uma conjuntura de desencadeamento.

Ela ocorre por ocasião de uma viagem à Sicília, aos 20 anos. Lá começa a namorar um jovem, mas logo rompe o namoro por solicitação dos pais. Após o término do namoro, é acometida por um apetite voraz que a faz engordar bastante, tornando-se objeto de críticas pejorativas por parte de suas amigas. Ellen é, então, atravessada pelo medo concreto de engordar. O medo concreto e localizado de engordar, de estar gorda, a leva a fazer longas caminhadas a ponto de se converter em errante, alguém que está despossuída de um lugar. Considerando as informações acerca da curva ponderal de Ellen West, presentes no Quadro 3, o medo de engordar está na base da ingestão de quantidades cada vez maiores de comprimidos de laxantes, a ponto de na época em que tentara o suicídio, por três vezes, estar consumindo entre sessenta a setenta comprimidos por dia: "Meu eu interior está tão intimamente fundido com meu corpo que ambos formam uma unidade, constituindo juntos meu 'eu', meu 'eu individual', nervoso ilógico. . . . Meus pensamentos estão exclusivamente fixos em meu corpo, minha comida, meus laxantes" (Ellen West, citada por Villegas i Besora, 1997, p. 40).

Dessa forma, contrariando as hipóteses diagnósticas clássicas já levantadas sobre o caso (psicastenia, histeria e neurose obsessiva grave com oscilação maníaco-depressiva) e o diagnóstico contemporâneo de transtorno alimentar, cabe interrogar se a irrupção do medo e a errância, no marco de um encontro amoroso que não é levado adiante pela paciente, não teriam sua etiologia localizada na foraclusão e seu efeito de vazio subjetivo e pregnância do eixo imaginário.

De fato, uma resposta afirmativa se impõe ao se constatar a preservação e a inflação do medo concreto de engordar no funcionamento psíquico de Ellen: em sua errância, nas tentativas de suicídio, na fixação do pensamento no corpo: "Sinto medo de minha fome porque não consigo pensar nem ver o mundo com clareza.... estou num calabouço e não posso sair... Tenho a impressão de ser um cadáver entre as pessoas" (Ellen West, citada por Tosta Berlinck \& Magtaz, 2008, p.235).

O trecho apresentado traz a tonalidade melancólica típica do luto pela perda da libido e da identificação do ser a sua pura e simples imagem como exposição desse luto. Dois outros trechos de seu testemunho, extraídos de Villegas i Besora (1997), vão à mesma direção expressando a posição subjetiva de Ellen West ao considerar sua vida como indecorosa e, consequentemente, indigna de ser vivida:

A morte é a maior felicidade na vida, senão a única. Sem a esperança do fim, a vida seria intolerável. A única coisa que me consola um pouco é a certeza de que tarde ou cedo, a morte chegará.... A vida se converteu para mim em um campo de 
concentração, e eu anseio a morte com o mesmo ardor com que o pobre soldado preso na Sibéria anseia regressar a sua pátria (Ellen West, citada por Villegas \& Besora, 1997, p. 40). teríamos:

Retomando o caso de Ellen West à luz da Figura 2,

\begin{tabular}{ll}
\hline $\begin{array}{l}\text { Phi0-Medo de engordar/ } \\
\text { Solução compensatória }\end{array}$ & $\begin{array}{l}\text { eu individual, nervoso } \\
\text { Nome própico }\end{array}$ \\
\hline
\end{tabular}

Figura 3.

O processo de superidentificação em Ellen West.

O esquema elaborado por Castanet e De Georges (2012) deixa claro que o medo de engordar que irrompe no marco término do namoro e o elenco de fenômenos clínicos de corpo a ele correlacionados (fusão entre o eu e o corpo, ser um cadáver, estar em um campo de concentração) responde à falência fálica típica da foraclusão (PHI0). O eu individual, nervoso ilógico é a solução compensatória para esses fenômenos, uma identificação do ser a sua pura e simples imagem, na ausência de um nome próprio (meu eu interior está tão intimamente fusionado ao теи согро).

É com esse quadro clínico que Ellen West dá entrada no Sanatório de Kreuzlingen e é a partir dele que decide dar fim a sua própria vida. De fato, a despeito de se submeter ao tratamento e ganhar algum peso, a experiência de medo concreto de engordar se mantém e a leva a mais uma tentativa de suicídio e, por fim, à interrupção do tratamento. Sua morte acontece no terceiro dia após a saída de Kreuzlingen, quando ingere uma dose de veneno e dá cabo de sua vida.

\section{Conclusão}

O estudo qualitativo aqui apresentado das principais referências teóricas em psicopatologia e em psicanálise permitiu interrogar a validade da caracterização da anorexia, tal como se apresenta no DSM-5, para elucidar o diagnóstico da recusa do alimento. Essa interrogação se encontra na base do avanço da pesquisa dos transtornos alimentares na direção de sua etiologia psíquica e, consequentemente, na direção de elucidá-la a partir dos processos psíquicos de recalcamento e foraclusão. Para isso, o artigo retoma as referências psicopatológicas clássicas sobre o tema da anorexia e estabelece um diálogo com as referências em psicanálise em especial, no que se refere aos determinantes psíquicos da psicose. A reconsideração do caso de Ellen West à luz da temática do diagnóstico de psicose nas patologias atuais permitiu evidenciar os efeitos da foraclusão e a tentativa de estabelecer uma solução compensatória para a foraclusão. Dessa forma, este trabalho mostrou que o conhecimento dos processos psíquicos em jogo na constituição da neurose e psicose, a partir do marco teórico da psicanálise, é uma ferramenta fundamental para a determinação da conjuntura etiológica de desencadeamento da recusa do alimento e, consequentemente, da elaboração mais precisa de seu diagnóstico para a direção de tratamento.

\section{Referências}

Alckmin-Carvalho, F., Santos, D. R., Rafihi-Ferreira, R. E., \& Soares, M. R. Z. (2016). Análise da evolução dos critérios diagnósticos da anorexia nervosa. Avaliação Psicológica, 15(2), 265-274. http://pepsic.bvsalud.org/scielo. php?script=sci_arttext\&pid=S1677-04712016000200016\&lng=pt\&tlng=pt

American Psychiatric Association. (1980). Diagnostic and Statistical Manual of Mental Disorders (3th ed.). Washington, DC: APA.

American Psychiatric Association. (2000). Diagnostic and Statistical Manual of Mental Disorders (4th ed.). Washington, DC: APA.

American Psychiatric Association. (2014). Manual Diagnóstico e Estatístico dos Transtornos Mentais (5a ed.). Porto Alegre, RS: Artmed.

Castanet, H., \& De Georges, P. (2012). Ligamentos, desligamentos, religamentos. In M. C. D. Batista \& S. Laia (Orgs.). A psicose ordinária. A Convenção de Antibes (pp. 21-52). Belo Horizonte, MG: Scriptum.

Cordás, T. A., \& Claudino, A. M. (2002). Transtornos alimentares: fundamentos históricos. Revista Brasileira de Psiquiatria, 24(Suppl. 3), 3-6. https://dx.doi.org/10.1590/S1516-44462002000700002

Cotard, J. (1998). Do delírio de negação. Revista Latinoamericana de Psicopatologia Fundamental, 1(4), 156-177. (Trabalho original publicado em 1882) 
Cottet, S. (1997). Gai Savoir et triste vérité. La Cause Freudienne: Revue de Psychanalyse, 35, 25-27.

Freud, S. (1982). O caso de Emmy Von N. In Edição standard brasileira obras psicológicas completas de Sigmund Freud (J. Salomão, Trad., Vol. 2, pp. 82-133). Rio de Janeiro, RJ: Imago. (Trabalho original publicado em 1893)

Freud, S. (1982). Rascunho G. In Edição standard brasileira obras psicológicas completas de Sigmund Freud (J. Salomão, Trad., Vol. 1, pp. 246-253). Rio de Janeiro, RJ: Imago. (Trabalho original publicado em 1895)

Freud, S. (1982). Notas psicanalíticas sobre um relato autobiográfico de um caso de paranoia (dementia paranoides). In Edição standard brasileira obras psicológicas completas de Sigmund Freud (J. Salomão, Trad., Vol. 11, pp. 231-244). Rio de Janeiro, RJ: Imago. (Trabalho original publicado em 1911).

Freud, S. (1982). Luto e melancolia. In Edição standard brasileira obras psicológicas completas de Sigmund Freud (J. Salomão, Trad., Vol. 14, pp. 243-263). Rio de Janeiro, RJ: Imago. (Trabalho original publicado em 1917[1915])

Gull, W. W. (1997). Anorexia nervosa (Apepsia hysterica, anorexia hysterica). Transactions of the Clinical Society, 5(5), 498-502. (Trabalho original publicado em 1874). https://doi.org/10.1002/j.1550-8528.1997.tb00677.x

Lacan, J. (1985). O seminário, livro 2: o eu na teoria de Freud e na técnica da psicanálise, 1954-1955. Rio de Janeiro, RJ: Zahar.

Lacan, J. (1992). Abertura da sessão clínica. Traço, 1, 2-5. (Trabalho original publicado em 1977)

Lacan, J. (1998). De uma questão preliminar a todo tratamento possível da psicose. In Escritos (pp. 537-590). Rio de Janeiro, RJ: Jorge Zahar. (Trabalho original publicado em 1957-1958)

Lacan J. (2002). O seminário, livro 3: as psicoses, 1955-1956. Rio de Janeiro, RJ: Zahar.

Lasègue, Charles. (1998). Da anorexia histérica. Revista Latinoamericana de Psicopatologia Fundamental, 1(3), 158-171. (Trabalho original publicado em 1873). https:// doi.org/10.1590/1415-47141998003011

Lutenberg, J. (2014). El vacío mental. Lima: Cauces Editores.

Maleval, J. C. (2014). Elementos para uma apreensão clínica da psicose ordinária. Clínica \& Cultura, 3(1), 105-169. https://seer.ufs.br/index.php/clinicaecultura/article/view/2841/2993

Miller, J. A. (1998). Lições sobre a apresentação de doentes. In J. A. Miller et al. (Orgs.). Os casos raros, inclassificáveis da clínica psicanalítica. A Conversação de Arcachon. São Paulo, SP: Biblioteca Freudiana Brasileira.

Miller, J. A. (2012). Efeito de retorno sobre a psicose ordinária. In M. C. D. Batista \& S. Laia (Orgs.). A psicose ordinária. A Convenção de Antibes (pp. 399-428). Belo Horizonte, MG: Scriptum.

Recalcati, M. (1997). Clínica del vacío: anorexia, dependencias, psicosis. Madrid: Editorial Síntesis.

Recalcati, M. (2011). La última cena: anorexia y bulimia. Buenos Aires: Ediciones Del Cifrado.

Redmond, J. D. (2017). Elementary phenomena, body disturbances, and symptom formation in ordinary psychosis (Doctoral thesis). Deakin University, Australia.

Silverman, J. (1997). Comments on the Therapeutic role of isolation in the treatment of anorexia nervosa. International Journal of Eat Disorder, 21(3), 295-298. https://onlinelibrary.wiley.com/doi/ full/10.1002/\%28SICI\%291098-108X\%28199704\%2921\%3A3\%3C295\%3A\%3AAID-EAT10\%3E3.0.CO\%3B2-\%23

Tosta Berlinck, M., \& Magtaz, A. C. (2008). Reflexões sobre O caso de Ellen West. Estudo antropológico-clínico de Binswanger. Revista Latinoamericana de Psicopatologia Fundamental, 11(2), 232-238. https://doi.org/10.1590/ S1415-47142008000200005

Villegas i Besora, M. (1997). Psicopatologías de la libertad (II): la anorexia o la restricción de la corporalidad. Revista de Psicoterapia, 3(30-31), 19-91. http://www.centroitaca.com/pdf/biblioteca/Anorexia_04.pdf

\section{Cláudia Henschel de Lima}

Pós-doutorado em Psicologia e docente colaboradora do Programa de Pós-Graduação em Psicologia da Universidade Federal do Rio de Janeiro (UFF). Docente permanente do Profiap-UFF. Professora associada I do Departamento de Psicologia da UFF, Volta Redonda - RJ. Brasil.

E-mail: claudialima@id.uff.br

(1) https://orcid.org/0000-0002-7693-7321 
Débora Assis de Souza

Mestranda pelo Programa de Pós-Graduação em Psicologia da Universidade Federal do Rio de Janeiro, Rio de Janeiro - RJ. Brasil

E-mail: debora.asouza@live.com

(1) https://orcid.org/0000-0003-1081-7594

Endereço para envio de correspondência:

Universidade Federal Fluminense. Rua Desembargador Ellis Hermydio Figueira, 783, Bloco A, sala 309, Aterrado.

CEP: 27213-145. Volta Redonda - RJ. Brasil

Recebido 13/01/2018

Aceito 22/08/2018

Received $13 / 01 / 2018$

Approved 22/08/2018

Recibido 13/01/2018

Aceptado 22/08/2018

Como citar: Henschel de Lima, C., \& Souza, D. A. (2020). Uma Hipótese Psicanalítica acerca do Desencadeamento da Anorexia na Psicose. Psicologia: Ciência e Profissão, 40, 1-15. https://doi.org/10.1590/1982-3703003190125

How to cite: Henschel de Lima, C., \& Souza, D. A. (2020). A Psychoanalytic Hypothesis about the Effects of Anorexia in Psychosis. Psicologia: Ciência e Profissão, 40, 1-15. https://doi.org/10.1590/1982-3703003190125

Cómo citar: Henschel de Lima, C., \& Souza, D. A. (2020). Una Hipótesis Psicoanalítica acerca del Desencadenamiento de la Anorexia en la Psicoses. Psicologia: Ciência e Profissão, 40, 1-15. https://doi.org/10.1590/1982-3703003190125 